APRESENTAÇÃO 


\section{APRESENTAÇÃO: NOTA DO EDITOR}


O Design é maneira distinta de interpretar, qualificar e/ou criar o mundo em que vivemos, no mínimo, enquanto simulacro, o mundo que desejamos viver. Desde 1808, através da Imprensa Régia, de um Brasil da Família Imperial Portuguesa de D. João VI e de Antonio Isidoro da Fonseca, vem-se aprimorando a prática do ofício das artes gráficas, não apenas pela evolução e desenvolvimento técnico de produção da página impressa (1746), mas também pela inspiração e resultado dos processos criativos e imaginários decorrentes da cultura visual que impulsionaram Zeferino Ferrez, em 1841, iniciar o ensino sistemático das artes e ofícios no Brasil. Ateliês litográficos, Imprensa Regia, Tipografias ou, mais precisamente, Oficina Litográfica do Arquivo Militar, Colégio das Fábricas, Litografia Leopoldo Heck, Typographia Universal de H. Laemmert \& C., Tipografia G. Leuzinger \& Filhos, do mesmo período dos artífices Romão Eloy de Almeida, Braz Sinibaldi e José Marques, legaram o parque gráfico desse país. Nação de Hipolito José da Costa Pereira Furtado de Mendonça (17741923), considerado o fundador da imprensa brasileira, e de outros tantos protagonistas da cultura visual e da comunicação impressa no Brasil.
Pelotas, nessa esteira, a partir da segunda metade do século XIX, fez-se cenário de referência às artes gráficas. Impulsionada pelo apogeu cultural e econômico, pelo acesso aos insumos europeus oportunizado pelo Porto de Rio Grande, o parque gráfico se qualificou através da importação de maquinário, dos clichês, papéis e tintas especiais importados da Europa, mais precisamente, oriundos de Portugal, Espanha, França, Alemanha e Inglaterra.

Em Pelotas, o ofício gráfico estabelecido pela produção de jornais diários, revistas e almanaques ilustrados, encontraram lastro na produção editorial, marcada pelo surgimento do periódico Diário Popular (27 de agosto de 1890) e, posteriormente, foram continuados pelo ensino sistematizado, perpassando as origens das artes aplicadas pela fundação da Escola de Artes e Ofícios (1917) e da Escola de Belas Artes (1949) As recorrências de tipografias, ateliês de gravura e instituições de ensino existentes, como a prática litográfica com sua produção de impressos efêmeros na virada do século XIX. O Pelotense, que iniciou a 07 de novembro de 1851 , produzido pelo tipógrafo rio-grandino Candido Augusto de Mello, já indicava a orientação vertiginosa que a produção gráfica seguiria, bem como os exemplares do "Álbum Literário" de 1875. Não obstante, entre outros inúmeros protagonistas, Eduardo Chapon (1852-1903) foi percursor da litografia em Pelotas, inaugurando nesse município a imprensa ilustrada e, assim, ilustrou a vida cotidiana do sujeito moderno através da técnica (arte) litográfica e, em memória, faz-se homenagem a ele, nesse 2018, nomeando Chapon esse cadernos de design. 
CHAPON, Eduardo. Jovem artista litógrafo, ilustrador, vindo da França, foi uma das grandes referências das artes gráficas no contexto internacional, nacional e local: verdadeiro expoente do parque gráfico pelotense com seus principais periódicos: o "Cabrion" (resultado da sociedade com Eduardo de Araújo Guerra) e a folha ilustrada "A Ventarola" (1887). Em Pelotas, fundou a Litografia Parisiense (1887) que, como segue anúncio publicado, atendia as expectativas do setor fabril, de uma produção técnica/estética qualificada e das exigências do seu respectivo mercado: nal e estética) atribuídos aos resultados atingidos, haja vista as diferentes soluções da imagem nos seus distintos processos técnicos: da gravura à simulação computacional.

No curso da prática estabelecida pela indústria, as técnicas envolvidas definiram os artefatos e, por eles, enunciaram-se possíveis interpretações da cultura e das tradições. O design, mediado pelas técnicas gráficas, adquiriu no seu processo de manufatura as características dos materiais locados para sua produção e registro que, paulatinamente, se automatizaram no amparo da mecanização, definindo padronagens e estilos característicos dos processos de fabricação mecânica (Paradigma da Fabricação) para posterior autonomia (Paradigma da Programação) advinda da informática e de suas inteligências artificiais: da robótica à cibernética, tornando-se assim máquina de discurso e agenciamento para a compreensão dos seus atores (escritor/leitor) e respectivos contextos.

O desenvolvimento dos meios técnicos, as respectivas tecnologias imbricadas por suas linguagens (tanto nas matrizes analógicas quanto digitais) e as interações de estilos influenciaram diretamente o design ao longo de suas práticas, bem como proporcionaram a reconfiguração de um mundo que se re[a]presenta não só mapeado, mas produzido e reproduzido em escalas e velocidades múltiplas e concomitantes, caracterizado pelo poder da circulação, da disponibilidade e do acesso de uma sociedade narrada, verdadeiramente

interfaceada, entre escrita e leitura computacional.
O distanciamento dos processos artesanais, originários na automatização e da expansão da indústria gráfica, segmentou os processos projetuais de concepção, produção e distribuição da informação. Nesse contexto, as práticas industriais orientaram aos projetos uma normatização técnica e projetual para a impressão nos seus diversos suportes, bem como orientou os respectivos valores (de qualidade funcio-

\begin{abstract}
este estabelecimento artístico, atualmente a par das mais produções (Guia Bemporat, 1908, p. 302).
\end{abstract} e por preços sem competência. É a única casa no Estado gosto inte dourado por processos mais modernos, tornando-o res fábricas de França, Itália e Alemanha, dispõe de produtos excelentes e muito vantajosos para a boa confecção de suas 
CHAPON, CADERNOS DE DESIGN, linha editorial do Colegiado de Design, Centro de Artes da Universidade Federal de Pelotas, tem como missão a extroversão do conhecimento. É instrumento dedicado às reflexões sobre o design, em específico sobre as especialidades do design gráfico e do design digital. Com base nas experiências científicas, estéticas e/ou profissionais, sejam da prática e/ou da teoria crítica, expõe reflexões atuais sobre método, memória, arte, técnica e linguagens da cultura visual e suas expressões.

CHAPON, CADERNOS DE DESIGN está subdividido em quatro seções: 1) Linguagens do Design: comunicação, cultura e arte; 2) Metodologias do Design: tecnologias, sistemas e processos; 3)Teorias do Design: história, filosofia e crítica; 4) Visualidades. Sua periodicidade é semestral. Editais e submissões através do link https://periodicos.ufpel.edu.br/ojs2/ CHAPON Cadernos de Design.

CHAPON, Cadernos de Design, produz e disponibiliza conhecimento sobre o panorama das artes gráficas, de modo a desenvolver ações educativas e culturais que possibilitem não apenas a apropriação da história e da memória social, mas a formação de público ao ofício. Como ação cultural, de natureza sócio-educativa, reitera as metas de qualificação de pesquisadores, bem como divulga e disponibiliza a produção científica, artística e cultural, posto que se delimita a um claro propósito de intensificar o conhecimento sobre o design, reafirmando a responsabili- dade com a dimensão da pesquisa, do ensino e da extensão na Universidade Federal de Pelotas.

CHAPON, CADERNOS DE DESIGN, como processo de aprendizagem, compreensão crítica da cultura visual, especificamente como atributo de [re]conhecimento e autoestima, impulsiona e garante visibilidade àquilo que, notoriamente, se faz referência acadêmica: crítica e criatividade.

CHAPON, CADERnos DE DEsIGN, produzindo, registrando e publicando conhecimentos acerca do design, objetiva ampliar o quadro de fontes de pesquisa e documentação sobre autoria, processos de produção e, consequentemente, resultados estéticos e comunicacionais do design gráfico e digital.

CHAPON, CADERNOS DE DESIGN aqui constrói suas reflexões, as registra, as disponibiliza e, consequentemente, dá acesso aos mundos potencialmente possíveis que esse fluxo permite. 


\section{EXPEDIENTE DA EDIÇÃO}

Chapon Cadernos de Design é uma publicação editada pelo Colegiado dos Cursos de Design da Universidade Federal de Pelotas a partir da seguinte estrutura:

\section{Editor-Chefe}

Prof. Dr. João Fernando Igansi Nunes, Universidade Federal de Pelotas, Brasil

\section{Editora Científica}

Profa. Dra. Helena de Araujo Neves, Universidade

Federal de Pelotas, Brasil

\section{Editores técnicos}

Profa. Dra. Nadia Miranda Leschko, Universidade Federal de Pelotas, Brasil (Submissão)

Profa. Dra. Lúcia Bergamaschi Costa Weymar,

Universidade Federal de Pelotas, Brasil (Identidade Visual)

Profa. Dra. Ana da Rosa Bandeira, Universidade Federal de Pelotas, Brasil (Projeto Gráfico)

Acad. Leonardo Barwaldt Buzó (Revisão)

\section{Projeto gráfico e diagramação}

Profa. Ms. Sibelle Carvalos de Medeiros

Acad. Caroline Elisa Gonçalves da Silva

\section{Seções temáticas}

1 Linguagens do Design: comunicação, cultura e arte - Editor: Prof. Dr. Lauer Alves Nunes dos Santos - Avaliadores: Profa. Dra. Chris de Azevedo Ramil, Prof. Dr. Guilherme Carvalho da Rosa, Prof. Dr. João Fernando Igansi Nunes, Profa. Dra. Lúcia Bergamaschi Costa Weymar

2 Metodologias do Design: tecnologias, sistemas e processos - Editor: Prof. Dr. Tobias

Tessmann Mülling - Avaliadores: Profa. Dra. Andreia Bordini, Profa. Dra. Cilene Estol Cardoso, Profa. Ms. Gissele Cardozo, Profa. Dra. Mônica Lima de Faria, Profa. Dra. Roberta Coelho Barros

\section{Teorias do Design: história, filosofia e} crítica - Editora: Profa. Dra. Paula Garcia Lima Avaliadores: Profa. Dra. Ana da Rosa Bandeira, Profa. Dra. Helena de Araujo Neves, Profa. Dra. Nadia Miranda Leschko

4 Visualidades do Design - Editora: Profa. Dra. Lúcia Bergamaschi Costa Weymar - Avaliadores: Profa. Dra. Ana Paula Penkala Dias, Profa. Ms. Vivian Herzog 